\title{
Deborah Hess, La poétique de renversement chez Maryse Condé, Massa Makan Diabaté et Édouard Glissant
}

\section{Alessandro Corio}

\section{(2) OpenEdition}

\section{Journals}

\section{Edizione digitale}

URL: http://journals.openedition.org/studifrancesi/9049

DOI: $10.4000 /$ studifrancesi.9049

ISSN: 2421-5856

\section{Editore}

Rosenberg \& Sellier

\section{Edizione cartacea}

Data di pubblicazione: 1 octobre 2008

Paginazione: 495

ISSN: 0039-2944

\section{Notizia bibliografica digitale}

Alessandro Corio, «Deborah Hess, La poétique de renversement chez Maryse Condé, Massa Makan Diabaté et Édouard Glissant», Studi Francesi [Online], 155 (LII | II) | 2008, online dal 30 novembre 2015, consultato il 11 janvier 2021. URL: http://journals.openedition.org/studifrancesi/9049 ; DOI: https:// doi.org/10.4000/studifrancesi.9049

Questo documento è stato generato automaticamente il 11 janvier 2021.

\section{cc) $(9)$}

Studi Francesi è distribuita con Licenza Creative Commons Attribuzione - Non commerciale - Non opere derivate 4.0 Internazionale. 


\title{
Deborah Hess, La poétique de renversement chez Maryse Condé, Massa Makan Diabaté et Édouard Glissant
}

\author{
Alessandro Corio
}

\section{NOTIZIA}

DEBORAH HESS, La poétique de renversement chez Maryse Condé, Massa Makan Diabaté et Édouard Glissant, Paris, L'Harmattan, 2006, pp. 294.

1 Lo studio di Deborah Hess, docente di letteratura francese e francofona alla Drew University (New Jersey, USA), si presenta come un interessante tentativo di applicare il paradigma e la teoria della complessità alle letterature afro-caraibiche, senz'altro caratterizzate, perlomeno a partire dagli anni Ottanta - il periodo da lei preso in considerazione - da un alto livello di complessità e di frammentazione, simboliche e testuali. È diventato un gesto oramai ricorrente quello di applicare allo studio del testo letterario, spesso in modo abbastanza superficiale ed affrettato, i paradigmi mutuati dalle scienze un tempo definite "esatte", gesto che richiederebbe, oltre che una solida conoscenza di entrambi i settori disciplinari, una serie di precauzioni metodologiche e critiche che evidenzino chiaramente i margini di applicabilità ed i limiti di tale approccio.

2 La Hess comincia il suo studio fornendo una definizione ed una descrizione, in termini succinti ma precisi, di ciò che si definisce, nel campo della fisica, un "sistema adattativo complesso" e che assurge qui a "modello" per l'analisi del testo letterario. Si tratta di un sistema che si presenta come essenzialmente dinamico e si definisce per uno stato di crisi che consente lo sviluppo di una serie di fenomeni non prevedibili, caratterizzati da una causalità non lineare e dalla forte presenza del disordine. Una serie di tratti che, 
secondo l'autrice, ritroviamo nel romanzo afro-caraibico contemporaneo, anch'esso caratterizzato dalla molteplicità dei dati, da un alto livello di disordine, da un rapporto sfumato tra l'ordine e il disordine, dalla frammentazione testuale e dalla complessità.

Il paradigma della complessità è tratto - oltre che dalla meccanica quantistica, dalla teoria della relatività e dalle teorie del caos - dalle scienze sociali e dalle nozioni di complessità delle strutture e delle dinamiche sociali e culturali. Ai nomi di Heisenberg, Bohr, Gödel, si affiancano quindi quelli di sociologi contemporanei come Balandier, Parsons, Morin e persino Huntington, col suo modello dello "scontro delle civiltà".

Per quanto riguarda, poi, il contesto storico-culturale e sociale cui si rivolge l'attenzione dell'autrice e degli autori studiati, la complessità è identificata, con un approccio a dir poco semplificatorio e sovraccarico di luoghi comuni non vagliati criticamente, in una serie di elementi storici "perturbanti", quali la colonizzazione o la tratta degli schiavi, che avrebbero introdotto elementi di disordine e di instabilità nelle società tradizionali, ritenute "semplici", "statiche" e "conservatrici", prima dell'incontro con l'Occidente. Un solo esempio: «Dans le cas de la colonisation française de l'Afrique, le changement socioculturel est le résultat d'une dialectique d'interaction conflictuelle entre un système traditionnel (sic) et un système moderne imposé de l'extérieur» (p. 42). Una simile visione, perché non appaia come un rigido luogo comune, andrebbe perlomeno argomentata e verificata con una serie di esemplificazioni concrete, riferendosi con precisione al ricchissimo corpus di studi etnografici, antropologici e di critica postcoloniale disponibili sull'argomento. Tra l'altro, una simile riduzione semplicistica a dei termini binari è l'esatto contrario di un approccio metodologico alla complessità.

Detto questo, e tralasciando altre più severe osservazioni su alcuni stereotipi ricorrenti, l'analisi condotta sul corpus letterario risulta, per quanto a tratti rigida e schematica, abbastanza precisa ed è condotta principalmente a livello del contenuto e delle strutture narrative, senza tralasciare gli aspetti stilistici, figurativi e simbolici. La Hess prende in considerazione, nello specifico, tre "testi complessi", Ségou di Maryse Condé, composto dai due romanzi Les murailles de terre (1984) e La terre en miettes (1985), la trilogia di Massa Makan Diabaté che ha come protagonista Kouta, composta da Le boucher de Kouta (1982), Le coiffeur de Kouta (1980) e Le lieutenant de Kouta (1979), ed infine Tout-monde (1993) di Édouard Glissant.

6 Senza soffermarci qui sull'analisi delle singole opere, la Hess identifica nell'approccio narrativo dei tre autori, che a dire il vero presentano elementi di forte eterogeneità quanto a scelte stilistiche e linguistiche e strutture e contenuti narrativi, una serie di fattori comuni che riassume nella categoria di "renversement", ossia di capovolgimento degli elementi che caratterizzano, secondo l'autrice, la letteratura "tradizionale" africana e le forme narrative del romanzo classico di matrice europea: "L'œuvre antillaise et africaine francophone se caractérise par une forme de renversement qui se manifeste dans les paradigmes, les points de vue, les catégories, les structures romanesques et les figures de style» (p. 259). Così, se l'epopea di Ségou, narrata da Maryse Condé, si caratterizza per una progressiva corruzione e disintegrazione delle strutture sociali e dei codici culturali tradizionali della società bambara, associati all'oralità, in seguito alle conquiste ed alle colonizzazioni islamiche e cristiane, la corruzione sociale subisce addirittura un incremento, nella trilogia di Kouta, col passaggio all'epoca post-coloniale ed alla modernità. In Glissant, poi, l'estrema frammentazione narrativa, dei punti di vista, delle strutture spazio- 
temporali, riflette il trauma di un popolo, quello antillese, che dopo la tratta vive una seconda diaspora in un mondo dove il centro è ovunque, $e$ in nessun luogo.

7 Le poetiche della complessità e del capovolgimento e le molteplici forme narrative che queste assumono nella letteratura africana ed antillese, riflettono quindi l'impossibilità di ricomporre un racconto unitario e lineare del mondo, che sembra aver perduto definitivamente i suoi punti di ancoraggio. 